Special issue of the 3rd International Conference on Computational and Experimental Science and Engineering (ICCESEN 2016)

\title{
Surface Carburizing by Valorization of Organic Waste
}

\author{
B. Boutessouna*, O. Allaoui and L.A. Allaoui \\ Laboratoire de Génie des Procédés, Université Amar Telidji, Laghouat 03000, Algérie
}

\begin{abstract}
The organic waste recycling problem remains an important economic issue for the industry, where much research is done in this area. In this study, we are interested in the enhancement of some organic waste from slaughterhouses (blood and horns) with two objectives: recycling wastes and producing cheap cement for surface carburizing. The waste is converted into coal and added to an activator to produce a solid medium, witch can be used for surface carburizing of carbon steels. Preparation of waste and physical and chemical carbonating of blood and horns resulted in production of coal, that was used as an effective carbon source for cementation treatment. Comparison of the obtained results with other works on carburizing treatment, using industrial solid mixtures, has shown that carburizing layers in both cases are very similar. Indeed, metallographic analysis, X-ray diffraction and Vickers hardness testing of obtained layers have led to results very similar to those in literature.
\end{abstract}

DOI: $10.12693 /$ APhysPolA.132.1173

PACS/topics: 81.65.-b, 89.60.-k

\section{Introduction}

Various surface treatments have been widely used in order to strengthen the surface of materials, to increase their performances [1-3]. Among those treatments, pack carburizing treatment (with coal as source of carbon) has been used for many years for hardening of the surfaces of steels.

Slaughterhouses generate large quantities of solid and liquid wastes, resulting in large amounts of environmental pollution that could compromise public health. The recovery of this waste is justified for two reasons:

1. Decongest storage areas, limit sources of pollution and protect the population in the neighborhood of public dumps.

2. Recover a source rich in organic matter and non organic elements.

The organic waste recycling problem remains an important economic issue for the environmental industry, where much research is done in this area [4-8]. In this study, we are interested in the valorization of some organic wastes from slaughterhouses (blood and horns) with two objectives: recycling wastes and producing cheap cement for surface carburizing. The waste is converted into coal and added to an activator to produce a solid medium witch can be used for surface carburizing of carbon steels.

The use of organic wastes from slaughterhouses as a source of carbon in surface treatments of steels can lead to material savings and can contribute directly or indirectly to the reduction of environmental and health impacts of these wastes.

\footnotetext{
* corresponding author; e-mail bel. boutassouna@lagh-univ.dz
}

\section{Experimental techniques}

In this study, we took blood and horns, disposed by the slaughterhouse of Laghouat in Algeria, as examples of organic wastes, for use as carbon sources in carburizing treatments of steels. Before applying the carbonization methods, the blood and horns were washed, dried, crushed and boiled for two hours to remove the fat.

In order to obtain the final coal, which can be used as a carbon source in the carburizing cements, two types of treatments have been carried out on blood and horns after the cleaning and drying operations:

- The first one is a physical process and it is carried out in three distinct stages: drying at about $170{ }^{\circ} \mathrm{C}$, followed by carbonization under a controlled atmosphere at $500^{\circ} \mathrm{C}$ for 6 hours and finally an activation step at $900^{\circ} \mathrm{C}$ for 48 hours.

- The second one is a chemical process and it consists of drying at about $170^{\circ} \mathrm{C}$, adding a dehydrating reagent (sulfuric acid) and finally charring at a temperature of $500{ }^{\circ} \mathrm{C}$ for 8 hours.

In order to be able to compare the efficiency of carbon, produced from organic waste (blood and horns), we carried out a carburizing treatment with cements containing coal from organic waste, as carbon source.

S235 steel was chosen as the base material for the surface treatments planned in this work. The chemical composition of this steel is given in Table I.

TABLE I

Chemical composition of S235 steel.

\begin{tabular}{c|c|c|c|c|c|c|c}
\hline \hline Elements & $\mathrm{C}$ & $\mathrm{P}$ & $\mathrm{S}$ & $\mathrm{Mn}$ & $\mathrm{N}$ & $\mathrm{Cu}$ & $\mathrm{Fe}$ \\
\hline Mass \% & 0.19 & 0.043 & 0.039 & 1.38 & 0.007 & 0.42 & Balance
\end{tabular}

X-ray diffraction was used to identify the quality of coal produced by physical and chemical process treatments of blood and horns. 
Optical microscopic observations of microstructures, obtained after carburizing, evaluate the efficiency of carbon sources used in carburizing cements.

Vickers hardness profiles of cemented specimens help to evaluate the depth of obtained carburized layers.

Carburizing treatments under the same conditions of time and temperature $\left(950^{\circ} \mathrm{C}\right.$ and 4 hours $)$ for all studied cements permit comparing the efficiency of carbon sources. In this work, in addition to the industrial cement, used as a reference, we investigate four different components, based on the carbon source (blood or horns) and the process used for their treatment (physical or chemical).

\section{Results and discussion}

\subsection{Preparation of carburizing cements}

The X-ray diffraction analysis of the carbons, obtained by physical and chemical processes, shows that in both cases the prepared carbon has simple hexagonal and centered hexagonal structure (Fig. 1).
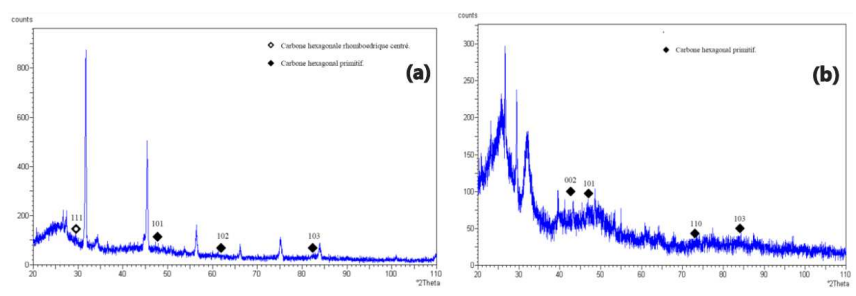

Fig. 1. Diffractogram of coal, obtained from blood and horns.

It should be noted that the chemical process shows better results in both cases. Indeed, in Table II, we can see that for the same quantity of $500 \mathrm{~g}$ of blood and horns, the efficiency of horns is better than that of blood, and that the chemical processes are more efficient than the physical ones.

TABLE II

Efficiency of physical and chemical processes in coal preparation.

\begin{tabular}{c|c|c}
\hline \hline Type of coal & Physical process & Chemical process \\
\hline Coal from blood & $75 \mathrm{~g}$ & $141.65 \mathrm{~g}$ \\
Coal from horns & $250 \mathrm{~g}$ & $300 \mathrm{~g}$
\end{tabular}

\subsection{Microstructure characterization}

To complement our study, we deemed it necessary to carry out microscopic observation of obtained microstructures, as a function of carbon source used in carburizing cement. In order to compare the efficiency of blood and horns, as carbon sources, we carried out carburizing treatment with carbon from these products and have compared the results with each other and with results obtained using commercial industrial cement.

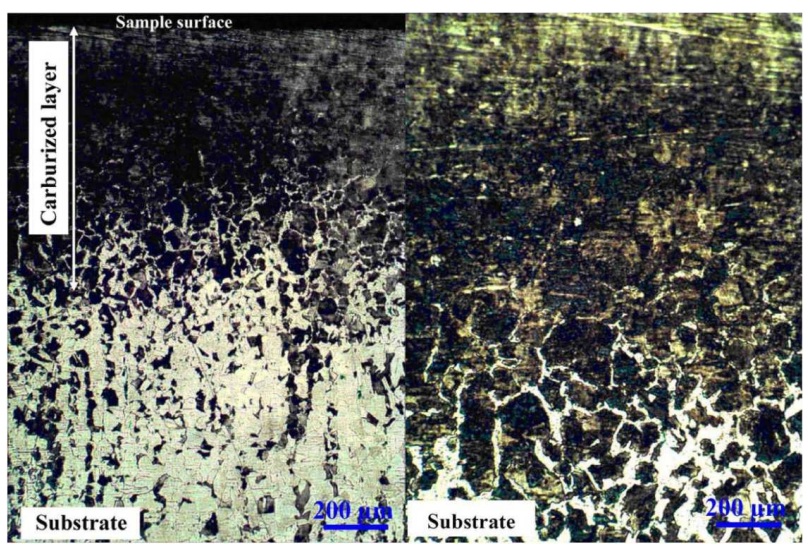

Fig. 2. Microstructure of S235 steel after carburizing in industrial cement $\left(950^{\circ} \mathrm{C}, 4\right.$ hours $)$.

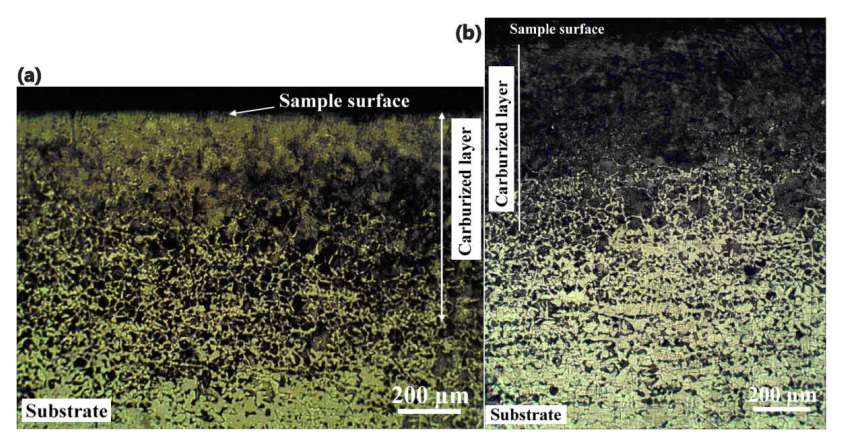

Fig. 3. Microstructure of S235 steel after carburizing in cement with carbon produced from blood: (a) chemical process; (b) physical process, $\left(950^{\circ} \mathrm{C}, 4\right.$ hours).

Figures 2-4 show the obtained microstructures of S235 steel after carburizing in industrial cement, a cement containing the blood coal as the carbon source and a cement containing the horns coal as the carbon source.

For comparison purposes, we have considered the amount of $0.8 \% \mathrm{C}$ as a reference for estimating the depth of cemented layer, produced on S235 steel. According to

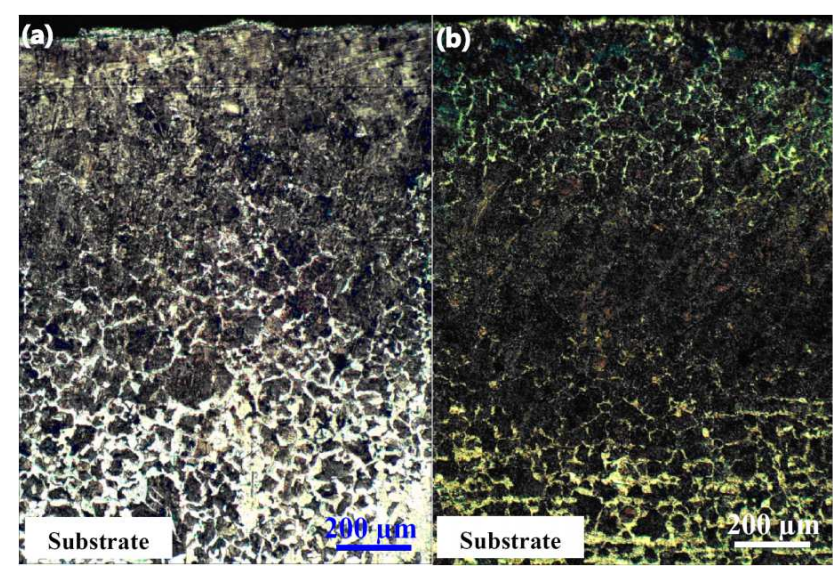

Fig. 4. Microstructure of S235 steel after carburizing in cement with carbon produced from horns: (a) chemical process; (b) physical process, $\left(950^{\circ} \mathrm{C}, 4\right.$ hours). 
this comparison criterion, the depths of cemented layers produced on the S235 steel, as functions of the chemical composition of carburizing cement, are summarized in Table III.

\section{TABLE III}

Carburized layer depth, as function of chemical composition of carburizing cement.

\begin{tabular}{c|c}
\hline \hline Chemical composition of carburizing cement & $\begin{array}{c}\text { Layer } \\
\text { depth } \\
{[\mu \mathrm{m}]}\end{array}$ \\
\hline $\begin{array}{c}\text { Industrial cement } \\
1100\end{array}$ \\
Blood coal "physical process" $+\mathrm{BaCO}_{3}+\mathrm{CaCO}_{3}$ & 500 \\
Blood coal "chemical process" $+\mathrm{BaCO}_{3}+\mathrm{CaCO}_{3}$ & 700 \\
Horns coal "physical process" $+\mathrm{BaCO}_{3}+\mathrm{CaCO}_{3}$ & 800 \\
Horns coal "chemical process" $+\mathrm{BaCO}_{3}+\mathrm{CaCO}_{3}$ & 700
\end{tabular}

The depth of the produced layer in this work is less than that achieved by Asuquo et al. [4], who have worked with various carburizing compounds. However, it should be noted that the achieved depth is large enough to be used on an industrial scale.

\subsection{Hardness characterization}

The values of Vickers hardness, from the surface to the core of carburized zone, in industrial cement, cement based on blood (physical process) and cement based on horns (physical process) are given in Table IV, where positions 1 to 4 are the same for all samples and refer to positions from surface, equidistant by $250(\mu \mathrm{m})$.

\section{TABLE IV}

Vickers hardness values of carburized zone from the surface to the core, as functions of carburizing cement.

\begin{tabular}{c|c|c|c}
\hline \hline & $\begin{array}{c}\text { Industrial } \\
\text { cement }\end{array}$ & $\begin{array}{c}\text { Cement based } \\
\text { on blood }\end{array}$ & $\begin{array}{c}\text { Cement based } \\
\text { on horns }\end{array}$ \\
\hline On surface & 559 & 504 & 576 \\
Position 1 & 499 & 454 & 492 \\
Position 2 & 393 & 333 & 396 \\
Position 3 & 311 & 241 & 318 \\
Position 4 & 180 & 154 & 151
\end{tabular}

Results in Table IV present a confirmation of the efficiency of the components used for the carburization of S235 steel. Indeed, the hardness values obtained for blood-based and horn-based cements are comparable with the hardness obtained for industrial cement.

\section{Conclusions}

The carried out work has led to the following conclusions:

- Blood and horns can be recycled and used as a carbon source in pack carburizing treatments.

- Blood and horns, as sources of carbon in the carburizing cement, lead to carburized layers with thickness up to $800 \mu \mathrm{m}$ on S235 steel.

- The effectiveness of horns as a source of carbon in carburizing cement is better than that of blood.

- The hardness values obtained using carbon in carburizing cements, produced form blood and horns, are comparable with hardness obtained from industrial cement.

\section{References}

[1] J.R. Davis, Surface Hardening of Steels: Understanding the Basics, ASM International, 2002.

[2] R.W. Foreman, Pack Carburizing of Steels, ASM Handbook, ASM International, Heat Treating, Vol. 4, 1990, p. 325.

[3] G. Parrish, Carburizing microstructures and properties, ASM International, 1999.

[4] L.O. Asuquo, I.P. Aondona, Int. J. Steel Res. Technol. 1, 12 (2013).

[5] F.O. Aramide, S.A. Ibotoye, I.O. Oladele, J.O. Borode, Leonardo Electr. J. Pract. Technol. 9, 1 (2010).

[6] A.P. Ihom, African J. Engin. Res. 1, 97 (2013).

[7] A.P. Ihom, G.B. Nyior, N.I. Justine, N.J. Ogbodo, Am. J. Mater. Sci. Engin. 1, 29 (2013).

[8] A.P. Ihom, G.B. Nyior, O.O. Alabi, S. Segun, N.I. Justine, N.J. Ogbodo, Int. J. Sci. Engin. Res. 3, 11 (2012). 